\title{
The Process of Becoming Black in Noviolet Bulawayo's We Need New Names
}

https://doi.org/10.33806/ijaes2000.21.1.12

\author{
Somia Ayaicha, Manimangai Mani, Hardev Kaur and Mohamed Ewan Bin \\ Awang \\ Universiti Putra Malaysia, Malaysia
}

\begin{abstract}
The bruised voices of African immigrants in America have been portrayed in contemporary African literature, such as NoViolet Bulawayo's We Need New Names (2013). According to Bulawayo's depiction, Darling is among those who are subjected to racial discrimination which was never an issue for them back in their countries. This article attempts to bridge the literary field with social psychological theories by examining the influence of African immigrants' social identifications and categorizations, using Tajfel and Tuner's Social Identity Theory. Moreover, the concept of individual mobility is explored as a coping mechanism by the immigrants to deal with their negative social identity. The second objective is the identification of the various phases that African immigrants go through during the process of becoming black. This can be achieved through the use of William Cross' Nigrescence Theory. A significant contribution of the present paper lies in analyzing African immigrants from a different perspective, focusing more on the journey of self-acceptance and the process of becoming black through the Nigrescence theory. The inclusion of these theories, namely Social Identity and the Nigrescence theory, is a broadening input in literary analysis since they have not been applied in previous literary studies.
\end{abstract}

Keywords: immigration, nigrescence theory, NoViolet Bulawayo, social identity theory (SIT), We Need New Names.

\section{Introduction}

Leaving your country is like dying, and when you come back you are like a ghost returning to earth, roaming around with a missing gaze in your eyes. (Bulawayo 2013:160)

NoViolet Bulawayo is the pen name of Elizabeth Zandile Tshele. She is the first Zimbabwean and black African woman to be shortlisted for the 2013 Man Booker Prize owing to her debut novel We Need New Names (2013). The latter is a continuation of her earlier short story "Hitting Budapest" (2010), which won the Caine Prize for African Writing. We Need New Names revolves around the journey of Darling from Zimbabwe to America. During the early 2000s, Darling used to live in Zimbabwe where her home was bulldozed due to a political turmoil. She was obliged to leave and settle in a new village they called Paradise: "We didn't always live in this tin, though. Before, we had a home and everything and we were happy... Now all we have is this small bed that sits on some bricks and poles" 
(Bulawayo 2013:62-63). Darling is depicted as a very smart and energetic girl who spends most of her time playing different games with her childhood friends, "They are the most important thing to me and when I'm not with them I feel like I'm not even me" (Bulawayo 2013:94). Together, they go to Budapest, where white rich people live, and steal guavas since it is the only source of food they could possibly find, "We just eat a lot of guavas because it is the only way to kill our hunger" (Bulawayo 2013:16). The narration differs from an engaging, energetic and exquisite in Zimbabwe into a quiet, introvert and broken voice of an immigrant in America.

The wretched situation that they were living in made the citizens leave the country in order to find jobs and be able to take care of their families. Darling's father went to South Africa for the sake of working but he ended up leaving his wife and daughter without any form of support. This behavior left an enormous impact on Darling as a young girl who needs not only shelter but her father's attention as well, she says: "Now Father is in South Africa, working, but he never writes, never sends money, never nothing. It makes me angry thinking about him, so most of the time I just pretend he doesn't exist; it's better this way" (Bulawayo 2013:22-23). However, she cherishes his existence and tries not to forget him, "by looking for him in the faces of the Budapest men, in the faces of my friends' fathers" (Bulawayo 2013:93).

Bulawayo depicted the massive traumatization caused by the armed mob rioting on the inhabitants of Paradise in general and on Darling specifically. She suffered from nightmares which kept her awake all night fearing the returning of bulldozers:

Now I am counting inside my head; this way I will not sleep. Nobody knows that sometimes I do not sleep... Even if I want to sleep I cannot because if I sleep, the dream will come and I don't want it to come. I am afraid of the bulldozers and those men and the police, afraid that if I let the dream come, they will get out of it and become real. I dream about what happened back at our house before we come to paradise. I try to push it away but the dream keeps coming and coming. (Bulawayo 2013:64-65)

This psychological instability at her age is quite effective and it destroys her sense of steadiness and well-being. The sudden incident left an instilled shock as Darling describes the terrible situation surrounding her at that moment, "When the bulldozers finally leave, everything is broken, everything is smashed, everything is wrecked. It is sad faces everywhere, choking dust everywhere, broken walls and bricks everywhere, tears on people's faces everywhere" (Bulawayo 2013:66). Her insecurity gets deeper when they move to Paradise and her life turns upside down because they become deprived of everything. The inhabitants feel disappointed by those who destroyed their land and properties, since they are supposed to stand by their side against the white colonizers and not the opposite, "Better a white thief do that to you than your own black brother. Better a wretched white thief" (Bulawayo 2013:75). 
The white settlers in Rhodesia institutionalized a system of racial segregation against the blacks and benefitted from the lands, since Zimbabwe is an agricultural powerhouse, "By apportioning the most arable land for whites, the white minority government succeeded in their efforts to politically, economically and socially disenfranchise the indigenous black Rhodesians. Their acquisition of arable land gave rise to a white bourgeoisie" (Cohen 2011:24). Therefore, the white colonizers became more powerful and affluent after taking over the agricultural lands unlike the aboriginal people, black Rhodesians who were deprived of their rights in their own country. At the helm of Mugabe, Zimbabweans were colonized by their own president who fought against the colonizers, "These and other legislated denials of rights and freedoms that were implemented under white minority rule have continually been utilized by Robert Mugabe for justification of continuing his dictatorial rule throughout his thirty plus years as President of Zimbabwe" (Cohen 2011:27-28).

Bulawayo highlights the injustices that the indigenous people have endured during the colonialism era through the voice of a child who can still see its lasting impact. Darling has a sarcastic way of thinking about the real intentions of whites while colonizing her country as people will never forget or forgive the crimes committed by the white settlers, "I don't know what the white people were trying to do in the first place, stealing not just a tiny piece but a whole country. Who can ever forget you stole something like that?" (Bulawayo 2013:20).

Zimbabweans have always been charmed by the whites, and have surrendered to the belief of the white supremacy which contributed to their immigration fantasies. Moreover, the tragic political, social and economic situation in Zimbabwe pushed the citizens to do anything in order to get out of country, "For the visas and passports, we begged, despaired, lied, groveled, promised, charmed, bribed- anything to get us out of the country" (Bulawayo 2013:240). Because they were always positioned outside the mainstream, Zimbabweans felt what is it like to be visible, recognized and worthy, even if that means to leave towards the unknown. This white supremacy and the dream of immigration exist not only with adults, but with children as well:

Who doesn't know that the U.S.A is the big baboon of the world? I feel like it's my country now because Aunt Fostalina lives there, in Destroyedmichygen. Once her things are in order she will come and get me and I will go and live there also. (Bulawayo 2013:49)

\section{Social Identity: African Immigrants' Displaced Identities}

The social psychologists Tajfel and Turner distinguished between the individual/personal and social identity. They based their theory on the social identity which is believed to be induced from group memberships. Therefore, individuals obtain their social identities through their in-group association and since immigrants' society changes drastically, they go through social identity alterations as well. According to the social identity theory, individuals might reach a point where their social identity is negative which imposes on them to use a certain coping mechanism to achieve a positive social identity instead (Brown 2000:747). 
Darling's self-esteem changes throughout the novel according to her social in-group and she strives to attain a satisfactory social identity.

Immigration obviously means a new society and brings radical changes for immigrants who find themselves in a whole different world. They immigrate with the eagerness to absorb the freshness of their dream country. Being an African immigrant in America, Darling is exposed to harsh racist treatments which made her very upset, "When I first arrived at Washington I just wanted to die... I just felt wrong in my own skin, in my body, in my clothes, in my language, in my head, everything" (Bulawayo 2013:165). Going through such traumatizing experience shook Darling's self-esteem and disturbed her self-perception because she was not only young and vulnerable, but because she was never treated like that before. She was always the loved friend and daughter back in Zimbabwe unlike her estranging status in America.

Darling could not support the disrespectful, degrading treatments of the Americans and thought about finding a solution for that, "I have decided the best way to deal with it all is to sound American... I also have my list of American words that I keep under the tongue like talismans, ready to use" (Bulawayo 2013:194). The importance of language in general and acquiring an American accent more specifically is highlighted by Bulawayo to stress the initial step toward seeking acceptance in the new society. Sounding an American will ease and speed up the process of assimilation and it will cover the smell of immigration, "I don't know why Aunt Fostalina doesn't think to learn America speech like this, seeing how it would make her life easier so she wouldn't have a hard time" (Bulawayo 2013:194).

Belonging to a given social group provides the individual with confidence, social support and safety. Reese et al. (2019:84) believe that, "As individuals most strongly identify with the social identities that maximally fulfil these needs, they also come to cherish them emotionally, and enact them often in daily life". Darling finds herself automatically categorized with Africans in America, this categorization imposed a low status and more marginalization. Hence, she refuses to belong to an inferior, subordinate group because according to Tajfel and Turner (1986:37), "this consensual inferiority is reproduced as relative self-derogation". Self-esteem is one of the most crucial motives that individuals seek in an in-group and its fulfilment will certainly strengthen the person's social identity.

The social identification with a certain social group inevitably makes the other groups as out-groups and the, "Ingroup-outgroup differentiation involves thinking of social groups or categories in us-them terms" (Brewer 2010:536-537). Darling's attempts to attain acceptance into an American in-group is initiated with her American accent regardless of the others' negative remarks, "trynna sound like stupid white folks" (Bulawayo 2013:222). Speaking and acting like Americans swallowed Darling's attachment to her friends and family who once meant the world to her, "With time I stopped writing altogether, I just started putting it off... before I knew it I'd lost touch" (Bulawayo 2013:188). Furthermore, Darling starts to be ashamed of how people from her country keep calling to ask for money and support, "The calls just keep coming and coming like maybe they've heard Aunt 
Fostalina is married to the Bank of America" (Bulawayo 2013:204). Their calls reinforce her belief that she came from a subordinate social group which will contribute to further derogate her identity among Americans.

Darling's decisions are basically enacted out of her negative discriminating experience since racism against blacks is found to be among the main reasons of anxiety, depression, suicide (Rogers-Sirin, Ryce and Selcuk 2014:13). Her identification with a different in-group got her carried away with being an American and living according to the America social norms, especially with her reckless friends who encourages her to watch porn videos on the internet to explore their sexualities. Darling has mixed feelings regarding the flicks they were watching sometimes they were interesting, exciting, quiet and at other times they were embarrassing, nasty and creepy.

Being wild and careless is something that Darling learns in America so that she will not be entitled a coward. Therefore, she pretends to be uncaring while she is hanging out with her friends who steal the car of Marina's mother and allow Kristal to drive it though she is violating the law since she does not have a driving license, "Kristal isn't old enough to have a license but that doesn't mean she can't drive" (Bulawayo 2013:215). At a moment, police follow them, "we hear the wailing sound, and we know that the police are chasing us. All the fun comes to a sudden end" (Bulawayo 2013:218), which frightens them especially Darling, "I think about opening the door and running, just running, but then I remember that the police will shoot for doing a little thing like that if you are black" (Bulawayo 2013:219).

\subsection{Negative Social Identity}

Putting her life at risk makes Darling feel uncomfortable and she cannot relate to her new, fake behaviour that she is wearing to impress people and to be accepted among Americans. She suddenly becomes aggressive against her friend and she blows up the truth about how she feels about her, "When I first met you, I couldn't understand anything coming out of your mouth, not a single word, nada, and you sit here and say you are American and that you speak English!" (Bulawayo 2013:221). Honesty relieves her a little bit but she cannot completely feel at ease with herself anymore.

All these drastic changes lead Darling to reach a state of instability and fragmentation. Her identity shatters between her pre and post immigration attitudes, "It's hard to explain, this feeling; it's like there's two of me" (Bulawayo 2013:210). Bulawayo deliberately shows this struggle that Darling undergoes to portray the dark side of the complete accumulation and assimilation into the host culture. Her categorization with the dominant social group is not enough to satisfy her individual needs which is alleged to be the primary aim of joining a superior in-group from the first place (Vignoles, Regalia and Manzi 2006:308).

She is torn between keeping up with her new American identity, which does not resemble her, or cherishing her African identity that she seems to miss. Darling's relationship with her friends and family trembles since she arrives to America especially when she stops writing to them. Cutting off all the ways of 
communication burdens Darling's conscious and the feeling of guilt overwhelmes her, "I feel a little guilty but I brush the feeling away" (Bulawayo 2013:210). There is an inner battlefield between her guilt and aspirations. Darling struggles when she reminisces her past and what she left behind, "I missed them, missed them very much, and there were these times when I'd be doing something and get this terrible feeling of guilt for not keeping in touch" (Bulawayo 2013:188). Then she remembers what she could be in her dream country, "You are in America now and you can actually be anything you want to be" (Bulawayo 2013:158).

Darling reaches a state where she criticizes all the American things that are supposed to please her after encountering various obstacles and losing her selfesteem:

No matter how green the maize looks in America, it is not real. They call it corn here, and it comes out all wrong, like small, sweet, too soft. I don't even bother with it anymore because eating it is really a disappointing thing, it feels like I'm just insulting my teeth. (Bulawayo 2013:164)

This new habit makes Darling partly satisfied since her America is not that perfect and at some points it seems even worse than Zimbabwe:

In America, the fatness is not the fatness I was used to at home. Over there the fatness was of bigness... It was fatness that didn't interfere with the body; a neck was still a neck, a stomach a stomach... but this American fatness takes it to a whole "nother level': the body is turned into something else- the neck becomes a thigh, the stomach becomes and anthill, an arm a thing, a buttock a I don't even what. (Bulawayo 2013:171)

This denunciation does not mirror her American identity. Instead, it gives her hidden African identity the chance to see the light under the imprisonment that is imposed on it. Darling spends a long time ignoring her feelings and the longing to her family to the point where she is surprised when she confronts her emotions, "Today, it's Mother on the phone. I am glad to hear her voice so I start smiling. I miss her so much sometimes it makes me dizzy but then there is nothing I can do about it" (Bulawayo 2013:204). The old Darling has very strong ties with her beloved friends whom she intentionally ignores in America:

I get goose bumps just from hearing them talk. There is a strange feeling coming over me and I feel this dizziness and I have to sit down. Time dissolves like we are in a movie scene and I have maybe entered the telephone and travelled through the lines to go home. (Bulawayo 2013:205)

The distant meeting of her friends through a tiny screen leaves an immense effect on Darling who surrenders to the inner yearning she holds for years:

Sbho is standing there watching her and eating a guava... I get a strange ache in my heart. My throat goes dry; my tongue salivates. I am remembering the taste of all these things, but remembering not tasting, and it is painful. I feel tears start to come to my eyes and I don't wipe them off. (Bulawayo 2013:209) 
This moment takes her back home when she was still a child and her only interest was to have fun with her friends while stealing guava to silence their hunger. Darling could not disregard and numb her feelings anymore as she feels more comfortable when she freely let go her yearning and she no longer hides it as she would usually do. Silencing her true sentiments is not the smartest thing that Darling opts for owing to its negative contribution to her identity deconstruction. Ignoring her inner voice and depersonalizing herself from the social group that she really belongs to shatter her identity and she never completely feels her true sense of self.

\subsection{Individual Mobility}

The initial purpose of categorizing oneself into a given social group is to gain a higher social status and to enhance one's self-esteem. If these are not attainable and the person is having a negative social identity, then s/he can opt for some coping mechanisms. Individual mobility is the most reliable mechanism in the case of Darling as for the permeability between both social groups which facilitates her movement from one group to the other, "Individual mobility is possible if the lines between groups are permeable, that is, flexible enough that individuals can move out of one social category and into another" (Reese, Amir and Cameron 2019:76).

Despite Darling's categorization with a high status in-group but this is not enough for her to reach a high level of self-esteem. It is very crucial to understand the concept of the self which is inseparable from the society as it was clarified by Roy F. Baumeister (2010:140) that:

The first job of the self is... to garner social acceptance. Beyond that, the self works to secure and improve its position in the social group. It keeps track of information about itself, works to improve how it is regarded by others, identifies itself with important relationships and roles, and makes choices (most of which are social).

Therefore, social acceptance within the ingroup is highly required; but since Darling can never detach herself from her Africanism, then her categorization with an American ingroup could not guarantee her a positive social identity.

Bulawayo succeeds to illustrate the failure of high status ingroup in assuring a high self-esteem and positive social identity. Therefore, Darling decides to individually mobilize herself towards another social group where she could be treated as equal as the other ingroup members without being racially discriminated against. Bulawayo's portrayal of the racial discrimination against her protagonist Darling is a mirror of the current racist situation in various western countries as Rohan and Zanna (1996) stated that, "Racist sentiments are still present in many individuals in contemporary society because these sentiments have been repeatedly (even if unwittingly) reinforced over the course of development by agents of socialization".

According to the social identity theory, people have their personal motives which lead them to take any decision and they differ from the collective and group- 
distancing motives. Becker and Barreto (2019:142) made a clear distinction between the previously mentioned motives where they stated that:

Personal motives refer to the wish of the individual to stop prejudicial treatment of the self as a target... Collective motives refer to the goal of stopping group-based discrimination, and it involves the aim to improve the conditions of the entire group... Finally, group-distancing motives aim at detaching the single individual from the group.

Darling's personal motive is mainly to regain her self-esteem and her sense of identity. It is believed that, "With an individual mobility mindset, people try to improve their individual position, because they believe that is the only way in which their social standing can be improved" (Becker and Barreto 2019:143). Therefore, this motive encourages Darling to change her social ingroup whereby the "social category becomes an outgroup only when the self is actively disassociated from the group, in a 'not-me' sense" (Brewer 2010:537) seeking solace in another ingroup where she comfortably feels right in her own skin without any obligations to change who she really is to be accepted and appreciated.

Darling cherishes the moments where Aunt Fostalina's African friends come to visit and those gatherings make her feel like home, "The onliest time that it's almost interesting here is when Uncle Themba and Uncle Charley and Aunt Welcome and Aunt Chenai and other all come to visit Aunt Fostalina" (Bulawayo 2013:160). The fact that she is surrounded by people who enjoy every aspect of being African regardless of their immigration to America is an incentive for Darling to set free her African self and be with the people she belongs to, "I think the reason they are my relatives now is they are from my country too- it's like the country has become a real family since we are in America, which is not our country" (Bulawayo 2013:161). Admitting that America is not her country is a huge step toward selfacceptance and self-love.

The American notions that used to captivate Darling since she was a child start to make none sense to her beginning from the simplest things like the sky which is not blue as Darling used to see in Zimbabwe:

The sky, for example, has stayed white all this time I have been here, which tells you that something is not right. Even the stones know that a sky is supposed to be blue, like our sky at home, which is blue, so blue you can put Clorox on it and wipe it with a paper towel and it wouldn't even come off. (Bulawayo 2013:151)

It is strange for Darling that even nature does not resemble what she has always seen back home. Even the most people that everyone look at and dream about being like them, Darling dislikes the beauty of the American models and she regards them as unattractive. She starts thinking about what they could be if they are in Zimbabwe, "If you were born in my country you'd just be ordinary, your run away would be the border, where you'd just be selling things like my mother" (Bulawayo 2013:149). This kind of beauty is not treasured in Zimbabwe unlike the American standards which glorify the bodies of size zero, "there is actually nothing 
African about a woman with no thighs, no hips, no belly, no behind" (Bulawayo 2013:151).

\section{The Process of Becoming Black}

\subsection{Pre-encounter}

Bulawayo's main character goes through a process of becoming black as it was elaborated by William E. Cross, Jr in his Nigrescence theory. Cross started his model with the pre-changing phases which he considered as important as the actual act of change that the blacks undergo since we cannot completely understand how an individual has transformed without knowing the initial phases of his life. Darling's pre-encounter stage is hypnotized by America long before she even migrates there to the point that she used to call it, "my America" (Bulawayo 2013:15). In Zimbabwe, most of the people are blown away by the western development and their biggest dream is to get out of their country as soon as possible. Their lives are fulfilled with the typical American dreams and Darling is no exception as she hallucinates about owning a luxurious car once she reaches America, "When I go to live with Aunt Fostalina, that's the kind of car I'll drive... I just know, because of this feeling in my bones, that the car is waiting for me in America" (Bulawayo 2013:111).

In their "Racial Identity Development During Childhood", Swanson, Cunningham, Youngblood and Spencer (2009:270) have highlighted the deep effects of the Eurocentric preferences of black children which leads to "a poor selfconcept and self-hatred". Consequently, it is evident that these pro-white feelings are instilled in Africans since childhood which justifies their eagerness to be accepted by the western society. During the process of seeking acceptance, Darling has opted for an American accent because she believes that, "to learn America speech... would make her life easier" (Bulawayo 2013:194). Migration at a very young age is an additional supporter for the quick assimilation of the young immigrant as for Darling who is already surrounded by the slogans of, "You are in America now and you can actually be anything you want to be" (Bulawayo 2013:158). Buying this belief of America is where dreams come true is an incentive for Darling to be at disposal of absorbing all the new and exotic life once she declares, "There were a lot of American words and things I was still learning" (Bulawayo 2013:166).

Throughout the narrative of the novel, we sense the clear and profound impact that the whites' supremacy ideology has left on Darling's personality. She is raised to the belief that, "everything in America was better" (Bulawayo 2013:189) which inevitably means that America is the dominant, superior country in comparison with home i.e. Zimbabwe which becomes the subordinate, uncivilized and miserable place. Privileging the white people and not just their countries is much worse as it made Darling always, "wonder how a white person's hair feels to the touch" (Bulawayo 2013:181) and feel the honour to speak to a white person, "I'm just proud that I'm finally talking to a white person, which I haven't ever done in my life" (Bulawayo 2013:129). If talking to a white person in Zimbabwe is 
regarded as something to brag about, then it is no wonder that living among them makes Darling impatient for their acceptance and approval.

Moreover, the deprivation and poverty that Africans suffer from plays a vital role in encouraging immigrants to assimilate into the host country as they find what they have always been lacking. For Darling, it was food that matters the most, "there is food to eat here, all types and types of food" (Bulawayo 2013:153). She suffers from hunger back in Zimbabwe and this makes her remember the times when she and her friends used to still guavas just to feed themselves, "In America we saw more food than we had seen in all our lives" (Bulawayo 2013:238). Another surprising news is the prohibition of child beating which is normal in Zimbabwe, and plastic surgeries that she looks at with amazement:

How America surprised us at first. If you were not happy with your body you could go to a doctor and say, for instance, Doctor, I was born in the wrong body, just make me right; Doctor, I don't like this nose, these breasts, these lips. We looked at people sending their aging parents away to be taken care of by strangers. We looked at parents not being allowed to beat their own children. We looked at strange things like these, things we had never seen in our lives. (Bulawayo 2013:239)

The huge difference between the home and the host cultures makes America even more interesting for Darling. Although the relationship between the age and the individual's racial identity is not supported by many researchers but some studies have shown that immigrants who come at an early age are more expected to be affected by the western subordination, "Black children growing up in Eurocentric environments would be more likely to develop pro-White attitudes" (Worrell 2008:161).

\subsection{Encounter}

The black immigrants, "experience a significant event or series of events that serve as a turning point in their racial identity development, leading to a reevaluation of their relationship to American society" (Worrell and Gardner-Kitt 2006:296). Darling has faced several events that urged her to re-evaluate her choices since she came to America because, "the encounter has a personally significant impact to be the catalyst to spur change in their thinking" (Ritchey 2014:103).

Darling recalls the words of her friend Stina about the country and they keep ringing in her ears due to their deep meaning which were not quite significant until she lived in America:

Stina said that a country is like a Coca-Cola bottle that can smash on the floor and disappoint you. When a bottle smashes, you cannot put it back together... Stina also said leaving your country is like dying, and when you come back you are like a ghost returning to earth, roaming around with a missing gaze in your eyes. I don't want to be that when I go back to my country. (Bulawayo 2013:160) 
One day, Darling encounters a harsh criticism from her mother through a phone call, "I see that America has taught you to speak English to your mother, and with that accent. He-he-he, so you are trying to sound white now!" (Bulawayo 2013:204). Her mother's denunciation leads Darling to unconsciously react as Americans do when they argue with their parents, "I start to call her crazy but I hold it and tell myself that it is one of the American things I don't want to do" (Bulawayo 2013:204). This reaction makes Darling think twice about her attitude and the values she learned back in Zimbabwe where elders' respect is a must.

Later, Darling hears the voices of her childhood friends and they take her back to relive the past:

I get goose bumps just from hearing them talk. There is a strange feeling coming over me and I feel this dizziness and I have to sit down. Time dissolves like we are in a movie scene and I have maybe entered the telephone and traveled through the lines to go home. (Bulawayo 2013:205)

The connection with her family and friends is an alerting signal for Darling to realize how much she misses her childhood, her stealing guava adventures, and her old self around the people who truly loved her, "Sbho is standing there watching her and eating a guava... I get a strange ache in my heart. My throat goes dry; my tongue salivates" (Bulawayo 2013:209). Once she arrives to America, she does not allow herself to surrender to her longing and she repeatedly ignores the feeling of guilt of not keeping in touch with her friends, "I feel a little guilty but I brush the feeling away" (Bulawayo 2013:210). However, at this stage Darling allows herself to cry for the yearning that has been imprisoned for years. She reaches a state where she could no longer suppress her feelings, "it is painful. I feel tears start to come to my eyes and I don't wipe them off" (Bulawayo 2013:209).

Another essential encounter is the fact that Darling's friend Chipo who was impregnated at a very young age had a daughter and she named her after Darling, "they claimed they decided to name her after me so there would be another Darling in case something happened to me in America" (Bulawayo 2013:210). It is a good initiation from her friends who like to feel her presence through naming Chipo's daughter after Darling but she could not completely swallow this act. This is like a call for the death of her old self since she left her country and stopped talking to her friends. Thus, Darling becomes confused and uncomfortable, "It's kind of cute, but I don't know how to feel about it, somebody being named after me like I'm dead or something" (Bulawayo 2013:210).

\subsection{Immersion-Emersion}

Cross (1991:202) clarifies that this stage represents "the vortex of psychological nigrescence" where the individual is ready to disregard his/her old Eurocentric perspectives and to build up a more suitable frame of reference. At the beginning of this stage, Blacks, "immerse themselves into their newfound Afrocentric world and begin to embrace all things Black; simultaneously there is a forceful rejection of that White or Eurocentric worldview held during the pre-encounter stage" (Cross 1991:73). When Darling is working for a white family, she meets their daughter 
who is suffering from anorexia for the sake of being slim and beautiful. This is very stressful for Darling and it teases her because she knows how it's really like to feel hunger and she condemns this behaviour, "Miss I Want to Be Sexy, there is this: You have a fridge bloated with food so no matter how much you starve yourself, you'll never know real, true hunger" (Bulawayo 2013:268). Darling rejects the whole western beauty standard and disqualified the thin girls who are considered as the models of attractiveness, "If you were born in my country you'd just be ordinary” (Bulawayo 2013:149).

Black individuals develop a strong sense of self-importance and pride toward their Black culture and heritage as it was explained by Cross (1991:203): immersion is a strong powerful dominating sensation that is constantly energized by rage (at White people and culture), guilt (at having once been tricked into thinking Black ideas), and developing a sense of pride (in one's Black self, in Black people, and in Black culture).

Darling notices how the switching back to the African accent makes her sound more authentic, "When I get excited I start to sound like myself, and my American accent goes away" (Bulawayo 2013:221). Faking the American accent is no longer desirable as Darling realizes that the sound of her true self will never be an American. One of the moments where Darling is with her friends, she is really astonished by her pride when she sees the picture of an African icon, "Nelson Mandela, I say, and I am surprised by the pride in my voice, like maybe I am talking about someone I know, like we used to play country-game together or something" (Bulawayo 2013:228).

At this stage, Darling becomes proud of her Black people and whenever they visit her in America she welcomes them with much love, "when they come to join us in America, hungry and hollow and hopeful, we held them tight and welcomed them to a home that was not ours. We smelled their hair and clothes, we begged them for news of our land" (Bulawayo 2013:246). According to Ritchey (2014:103), Black individuals "decompress all the negative stereotypes associated with being Black, and view being Black through a different lens" which is so relevant with Darling who reaches a state of peace with her Black culture. One day, she found a piece of cloth in the basement of Aunt Fostalina's house:

Looking at the cloth I'm remembering how beautiful it felt to be in a real scene like that, everybody just there together, mingling together, living together, before things fell apart. I begin to feel this ache in my heart that always comes when I think of my home. (Bulawayo 2013:283)

A single piece of cloth could have a huge impact on Darling with her vulnerability towards her Black culture and she quickly finds herself traveling back home, remembering all the good memories before things fell apart i.e. before immigration.

In her narrative, Bulawayo is very careful in her choices to better mirror specific messages through symbols like the mask that Darling finds in the basement, 
I find a weird mask; it's split in the center. One half white, the other black. The black half is split further in numerous crazy patterns that I can't figure out, but it looks interesting... When I have finished covering the wall, the mask is looking at me with the puzzling face; it's like it's trying to tell me something that will take years to understand. Next to it, the clock is telling a broken time. (Bulawayo 2013:283)

The mask represents Darling's torn identity between the whites and Blacks perspectives. The latter is further split into various patterns which stands for the fragmented identity of the Blacks before and after immigration. Darling's new decoration seems to be complete but at the same time it's still not what Darling really wants, "Look around my room; it looks complete, but I feel like I can't breathe from missing it" (284). At the end of this stage, the black individual is supposed to gain control over his/her romanticized feelings which indicates the emersion stage as it was described by Cross (1991:207):

An emergence from the emotionality and dead end, either/or, racist and oversimplified ideologies of the immersion experience. The person regains control of his or her emotions and intellect. In fact, he or she probably cannot continue to handle the intense emotional phase [of immersion] and is predisposed to find a way to level off.

\subsection{Internalization}

The current stage marks a new emerged Black identity that the individual is completely proud of. Darling starts caring about how she views herself and not how people view her unlike the pre-encounter stage where she was eager for the whites' acceptance. Therefore, Darling's identity is more stable and balanced, "the internalization marks the point of dissonance resolution and reconstruction of ones steady state personality and cognitive style" (Cross 1991:220). Through the internalization phase, Darling embraces all what is Black which enables her to reach a self-love since, "Black identity functions to fulfil the self-protection, social anchorage, and bridging needs of the individual" (Cross 1991:220).

Darling's desire to go back to Zimbabwe is so elevated the more she spends time in America and she keeps complaining about it, "In America, roads are like the devil's hands, like God's love, reaching all over, just the sad thing is, they won't really take me home" (Bulawayo 2013:191). Darling insists on the different meanings of home according to every person, "When somebody talks about home, you have to listen carefully so you know exactly which one the person is referring to" (Bulawayo 2013:192). She further elaborates that, "There are two homes inside my head: home before Paradise, and home in Paradise" (Bulawayo 2013:191) but she does not mention America as a home for her. The same goes for her Mother and her Aunt Fostalina, "There are three homes inside my Mother's and Aunt Fostalina's heads: home before independence... Home after independence... And then the home of things falling apart, which made Aunt Fostalina leave and come here" (Bulawayo 2013:191). Darling comes to the realization that America will never be home for Black immigrants. 
This awareness leads Darling to excessively think about going back home but Aunt Fostalina does not allow her, "You came on a visitor's visa, and that's expired; you get out, you kiss this America bye-bye" (Bulawayo 2013:189). Since Darling's studies are not completed, she could not move out of America until she gets her diploma, which she is hardly working for to pay her tuition fees. The financial dependency that Darling undergoes ties her in America. Darling came to America primarily to study; and not completing this goal prevents her from leaving. Even when choosing her field of study at the University, she is limited by choosing only the ones that really matter in America, "These... are the careers that count, and I didn't come all the way to America to do meaningless stuff and be nothing" (Bulawayo 2013:275). Therefore, Darling's desire to go back home is put on hold until she completes her studies and attains her financial independence, so that she could go back to Zimbabwe without waiting for the permission of Aunt Fostalina.

\section{Conclusion}

The aim of this paper is to unpack the racial layers of what the American psychologist William E. Cross, Jr has termed as the Nigrescence theory. Bulawayo portrayed the life of African immigrants in contemporary America through knitting a well-crafted story that captures the journey of a young Zimbabwean female who immigrates to the United States with a luggage of dreams. This paper has analyzed the main character through the lens of social psychological theories, namely the Social Identity and the Nigrescence theories. The displacement brings life changing experiences which shatter Darling's identity, starting from the drastic social and cultural transformations. Bulawayo succeeded at depicting the single story behind the Africans' dream of displacement as she was, "a channel to voice the untold stories" (Ammari, Allawzi and Al-Shara 2019:211). Eventually, immigrants suffer from a negative social identity due to the accumulated deceptions, and they struggle to cope with all the changes that they encounter in a very short time. By projecting the concepts of this theory on the immigrant characters of the selected novel, it has been possible for the readers to address the impact of racial discrimination and social inequality in moulding the African immigrants' racial identity. The Nigrescence theory operates as a mirror to the process of how an African immigrant embraces his black identity through protruding out the pervasive social and psychological trauma that Africans endure. It has been of great importance to dismantle the various social identifications and categorizations that immigrants adopt for the sake of gaining social recognition. This has been achievable through the analysis of Darling, as an immigrant character, using Tajfel and Turner's social identity theory. Moreover, the second aim of this study has been to analyse Darling's process of becoming black utilizing Cross' Nigrescence theory. As a result, Darling has experienced a drastic social and cultural change after her immigration which was a tough challenge for her to retain a stable identity. Therefore, she socially identified and categorized herself as an American which resulted into a distorted and ambiguous identity. Darling has gone through various stages to finally reach a state of self-love and acceptance as an African instead of forcing herself to become an American. This is the auspicious outcome that this 
study strived to highlight because Darling mirrors what a great number of immigrants go through. At the end, it is crucial to emphasize on the struggle that immigrants endure during their journey of self-discovery due to the difficulty to pass from self-hatred to self-love. The immigrants' process of appreciating their African identity is our most celebrated finding especially that it is derived from a literary analysis through the application of enriching social and psychological theories. This study paves the way for other future researches in the literary field using the social identity and Nigrescence theories to further understand the immigrants' displaced identities and how they can embrace their black identity after immigration.

Somia Ayaicha

English Department, Faculty of Modern Languages and Communication Universiti Putra Malaysia, Malaysia

ORCID Number: 0000-0002-3888-8784

Email: ayaicha.somia@hotmail.com

Manimangai Mani

English Department, Faculty of Modern Languages and Communication Universiti Putra Malaysia, Malaysia

Email: manimangai@upm.edu.my

Hardev Kaur

English Department, Faculty of Modern Languages and Communication Universiti Putra Malaysia, Malaysia

Email: hardevkaur@upm.edu.my

Mohamed Ewan Bin Awang

English Department, Faculty of Modern Languages and Communication

Universiti Putra Malaysia, Malaysia

Email: ewan@upm.edu.my

\section{References:}

Ammari, Deema, Areej Allawzi and Zaydun Al-Shara. (2019). 'Diaspora Reversed: A Post-Modern 'Third Space' in 'The American Granddaughter'. International Journal of Arabic-English Studies, 19 (1): 209-226.

Becker, Julia C. and Manuela Barreto. (2019). 'Personal, collective, and groupdistancing motives underlying confrontation of prejudice'. In Robyn K. Mallett and Margo J. Monteith (eds.) Confronting Prejudice and Discrimination: The Science of Changing Minds and Behaviors, 141-158. Academic Press. 
Brewer, Marilynn B. (2010). 'Intergroup Relations'. In Roy F. Baumeister and Eli J. Finkel (eds.) Advanced Social Psychology: The State of the Science, 535571. Oxford University Press.

Brown, Rupert. (2000). 'Social Identity Theory: Past Achievements, Current Problems and Future Challenges'. European Journal of Psychology, 30:745-778.

Bulawayo, NoViolet. (2013). We Need New Names. New York: Little Brown.

Cohen, Andrea. (2011). National Identity and Post-Colonial Development: Dictatorial Zimbabwe and Democratic Republic of South Africa. MA Thesis, Brandeis University, Massachusetts, United States.

Cross, William. E. Jr. Shades of Black: Diversity in African-American Identity. Philadelphia: Temple University Press, 1991.

Reese, Gerhad, Rosenmann Amir and James E. Cameron. (2019). 'The Interplay Between Social Identities and Globalization'. The Psychology of Globalization Identity, Ideology, and Action. 71-99. Elsevier.

Rohan, M. J., and Zanna, M. P. (1996). 'Value transmission in families'. In C. Seligman, J. M. Olson, \& M. P. Zanna (eds.), The Psychology of Values: The Ontario Symposium, Vol. 8:253-276. New Jersey: Lawrence Erlbaum.

Rogers-Sirin, Lauren, Patrice Ryce and Selcuk Sirin R. (2014). 'Acculturation, Acculturative Stress, and Cultural Mismatch and Their Influences on Immigrant Children and Adolescents' Well-Being'. In Radosveta Dimitrova et al., Global Perspectives on Well-Being in Immigrant Families, 11-30. New York: Springer.

Swanson, D. Phillips, Michael Cunningham, Joseph Youngblood and Margaret Spencer B. (2009). 'Racial Identity Development During Childhood'. In Neville, B. M. Tynes \& S. O. Utsey (eds.) Handbook of African American Psychology, 269-281. Thousand Oaks, CA: Sage Publications.

Tajfel, H., \& Turner, J. C. (1986). 'The social identity theory of intergroup behavior'. In S. Worchel \& W. Austin (eds.) Psychology of intergroup relations, 33-48. Chicago: Nelson-Hall.

Vignoles, Vivian L., Jen Golledge, Camillo Regalia, Claudia Manzi and Eugenia Scabini. (2006). 'Beyond Self-Esteem: Influence of Multiple Motives on Identity Construction'. Journal of Personality and Social Psychology, 90 (2):308-333.

Worrel, Frank C. (2008). 'Nigrescence Attitudes from Adolescence to Adulthood'. Journal of Black Psychology, 34 (2):156-178.

Worrel, Frank C. and Gardner-Kitt, Dona L. (2006). 'The Relationship Between Racial and Ethnic Identity in Black Adolescents: The Cross Racial Identity Scale and the Multigroup Ethnic Identity Measure'. Identity: An International Journal of Theory Research, 6 (4):293-315. 